\title{
The Effects of Prenatal Norharman Exposure on Seizure Severity in Rats
}

\author{
Mohammad Hossein Esmaeili $^{1} \mathbb{D}$, Mohammad Sofiabadi ${ }^{1 *} \mathbb{C}$, Amin Afshar $^{1}$ \\ 1. Department of Physiology, Faculty of Medicine, Qazvin University of Medical Sciences, Qazvin, Iran.
}

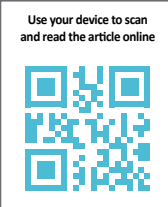

Cfit on Esmaeili MH, Sofiabadi M, Afshar A. The Effects of Prenatal Norharman Exposure on Seizure Severity in Rats. J Inflamm Dis. 2021; 25(1):19-24. http://dx.doi.org/10.32598/JQUMS.25.1.3

http://dx.doi.org/10.32598/JQUMS.25.1.3

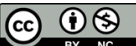

Article info:

Received: 12 Oct 2020

Accepted: 17 Mar 2021

Publish: 01 Apr 2021
Keywords:

Norharman, Seizure, Pentylenetetrazol, Rat

\section{ABSTRACT}

Background: Norhraman is an alkaloid that can damage the nervous system.

Objective: This experimental study aimed to investigate the effects of prenatal norharman exposure on seizure severity in adult rats.

Methods: A total of 36 Wistar rats were randomly divided into 3 groups as follows: Control, sham (solvent), and norharman $(1000 \mathrm{ug} / \mathrm{kg})$. The sham and norharman groups were treated once daily for $8-18$ of the fetal period. 2 months after birth, kindling was performed by the daily injection of Pentylenetetrazol (PTZ) $(30 \mathrm{mg} / \mathrm{kg})$; then, the seizure behavior was recorded for approximately 30 minutes. The obtained data were analyzed using Analysis of Variance (ANOVA) and Tukey's posthoc test.

Results: The present study data indicated that administrating norharman in the fetal period increased seizure responses to PTZ, i.e., significant in the examined female rats $(\mathrm{P}<0.05)$.

Conclusion: According to the current research findings, the severity of seizures increases in subjects who have been exposed to norharman during the prenatal period.

\section{Introduction}

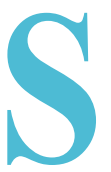

eizures are defined as a sudden change in the function of the Central Nervous System (CNS) caused by the excessive depletion of neurons [1]. Seizures, at different ages, can have numerous causes, such as metabolic, structural, and pharmacological impairments, CNS infections, including meningitis and encephalitis, vascular trauma, and hemorrhagic strokes
[2-4]. Seizures occur following a disturbance in the balance between the excitatory and inhibitory systems of the brain. This imbalance can be genetic or acquired [5].

In patients with epilepsy, the prevalence of cardiovascular, respiratory, and inflammatory diseases, diabetes, obesity, migraine, and arthritis has been reported to be further, compared to the general population. Moreover, these patients are at higher risks for bone fractures as well as sudden unexplained death [6]. Several models

* Corresponding Author:

Mohammad Sofiabadi

Address: Department of Physiology, School of Medicine, Qazvin University of Medical Sciences, Qazvin, Iran.

Phone: +98 (28) 33236001

E-mail: mohasofi@yahoo.com 
are used to induce acute and chronic chemical, electrical, and pneumatic seizures $[6,7]$.

Pentylenetetrazole (PTZ) is a GABA-A receptor antagonist. The Intraperitoneal (IP) injection of PTZ into an animal induces an acute and severe seizure at a high dose, while consecutive injections of a sub-convulsive dose have been used for generating chemical kindling, as an epilepsy model. Repetitive low-dose $(30 \mathrm{mg} / \mathrm{kg})$ injections of PTZ decrease the threshold to induce a convulsive seizure [7]. Norharman, as an alkaloid, is present in the seeds and roots of pecan. There are 5 alkaloid derivatives with indole structure in this plant, which include norharman, harman, harmin, harmaline, and harmalol, as the most well-known derivatives of beta-carbolines [8]. Norharman and harman are found in cigarettes, brewed coffee, meat extracts, and heat-cooked protein foods, as well as alcoholic beverages [9]. Additionally, beta-carbolines tend to attach GABA-A receptors and produce the opposite agonist effects; accordingly, they can cause seizures in high and anxious subjects in moderate doses [10-14]. The GABAergic system is the major inhibitory system of the brain; its suppression harms the balance of neuronal discharge. Thus, it increases the excitability of the brain and facilitates an increased susceptibility to seizures and the intensification of seizures [13]. Furthermore, norharman, as an active endogenous substance, can play a modulating role in cognitive function, especially in female rats [15].

Numerous studies have reported the bio-pharmacological effects of beta-carbolines on the eukaryotic and prokaryotic cells; subsequently, such impacts lead to changes in DNA replication and enzymatic activities involved in DNA sequencing [10]. Likewise, injecting beta-carbolines into the substantia nigra may cause neuronal damage by inhibiting TPI triphosphate isomerase [16]. Some reports have indicated its adverse effects on this maternal during organogenesis, which resulted in different constant defects [17].

The main growth and development of the CNS occur during the embryonic period, based on the aforementioned points; the exposure of the embryo to beta-carbolines may affect its susceptibility to seizures. Using norharman-containing substances is significantly on the rise. Thus, this study aimed to evaluate the effects of norharman administration on the severity of pentylenetetrazole-induced seizures in pregnant rats' offspring in adulthood.

\section{Materials and Methods}

In total, 30 pregnant female Wistar rats (200-230 g) were obtained from Pasteur Institute (Karaj City, Iran). The examined animals were housed in standard polycarbonate cages in the animal room under $12: 12 \mathrm{~h} \mathrm{light/dark}$ cycle at $22-20^{\circ} \mathrm{C}$, a humidity of $55 \%-45 \%$, and access to food and water ad libitum.

This randomized experimental trial was conducted at Qazvin University of Medical Sciences, in Qazvin City, Iran, in 2020. Initially, the study rats were divided into 3 groups, as follows: control (normal pregnancy), sham $(0.2 \mathrm{~mL}$ ethanol as solvent), and norharman (1000 $\mu \mathrm{g} /$ $\mathrm{kg}$ ). The sham and norharman groups were given solvent or norharman (Sigma-USA) by gavage once a day for 10 days from the eighth to $18^{\text {th }}$ day of pregnancy. The 36 offspring were randomly weaned 30 days after birth and separated by gender.

The kindling was performed 2 months after birth by daily IP injection of PTZ at a dose of $30 \mathrm{mg} / \mathrm{kg}$. Immediately after PTZ injection, the study animals' behaviors were precisely monitored for $30 \mathrm{~min}$. The tests were performed under standard conditions from 9 AM to $12 \mathrm{PM}$.

To observe the examined animals' behaviors, a transparent polygalas container $(30 \times 30 \times 30 \mathrm{~cm})$ was used. Following PTZ injection, each animal presented a set of spontaneous behaviors whose severity was graded in 5 scores, as follows: 0: no response, 1: ear and face jumps, -2 : body myoclonic jumps, 3 : myoclonic jumps, a sitting position with bilateral clonus of the forearms, 4 : toniccolonic seizures, and 5: general tonic-colonic seizures and falling (the loss of the position). In experiments, the highest response was considered in each animal, and in the event of stage 4, the explore rat was considered kindled. Additionally, each study group that reached stage 4 earlier was considered more sensitive to the seizure effect of PTZ [18]. The data were analyzed in SPSS using one-way Analysis of Varanine (ANOVA). Differences between the research groups were determined by Tukey's test at $\mathrm{P}<0.05$.

\section{Results}

Comparing the effects of norharman on PTZ-induced seizure in the male rats suggested the following findings:

Seizure severity and scores after injecting PTZ, in the norharman group were significantly higher than those in the control and solvent groups $(\mathrm{P}<0.05)$. Besides, in the norharman group, the time for all rats to reach stage 


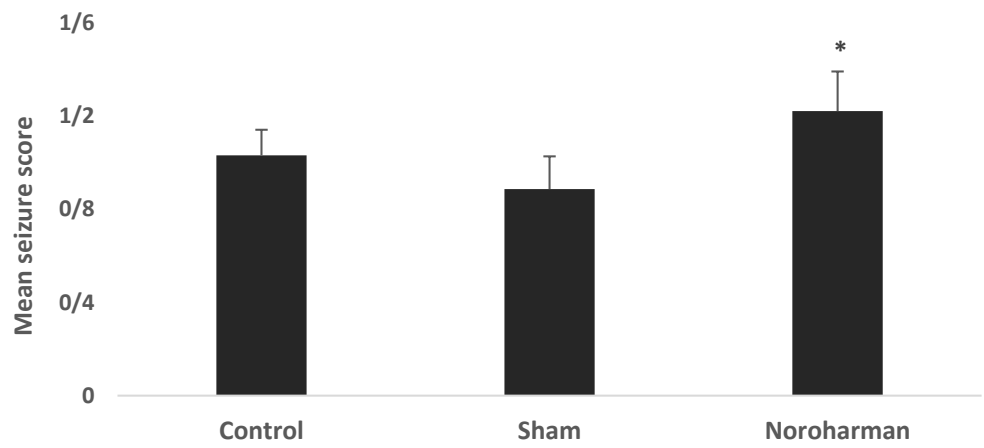

Figure 1. Comparing the Mean $\pm S E M$ scores of PTZ-induced seizures in male rats

Journal of Inflammatory Diseases

Consuming norharman significantly intensified PTZ-induced seizures in male animals $(\mathrm{n}=8)$, "P<0.05, compared with the control and solvent groups.

4 seizures was shorter than that in the controls. Correspondingly, the largest difference in the severity of seizures between the norharman group and the other study groups was detected during the $11^{\text {th }}$ to $15^{\text {th }}$ days after PTZ injection (Figures 1 and 2).

Comparing the effects of norharman on PTZ-induced seizures in the female rats, the results signified that the prenatal administration of norharman resulted in a higher significant score of PTZ-induced seizures, compared to the control and solvent groups $(\mathrm{P}<0.05)$ (Figure 3$)$. Norharman also significantly reduced the incidence time of severe seizures, compared with the control and sham groups. The mean seizure scores after PTZ injection during the sixth, and eighth to thirteenth days in the norharman group were higher than those in the other research groups. There was no significant difference between the control and sham groups in this respect (Figure 4).

\section{Discussion}

This study evaluated the effects of fetal norharman exposure on the seizure sensitivity of offspring by the pentylenetetrazole model in male and female rats. The collected results suggested that receiving norharman in the embryonic period increases the response to PTZ, especially in female rats. According to these findings, individuals who have been exposed to norharman during pregnancy are probably more prone to experience seizures, compared to the general population. Studies explored the effect of abusing some drugs and compounds during the fetal period on the structure and behavior of living organisms; however, the effects of norharman embryonic reception on the seizure sensitivity of offspring remains unstudied. Most similar studies have emphasized the negative impact of using these compounds in the physiological processes of the CNS or other organs of the body. For example, drug use, especially morphine, during pregnancy has been reported to impair spatial learning in rats; this occurs by altering opioid receptors, as well as differences in response to pain stimuli, compared with healthy rats $[19,20]$. In this regard, it has been claimed that even changes in the normal concentration of some maternal hormones during pregnancy cause alternations in the structure of the hippocampus; thus, this

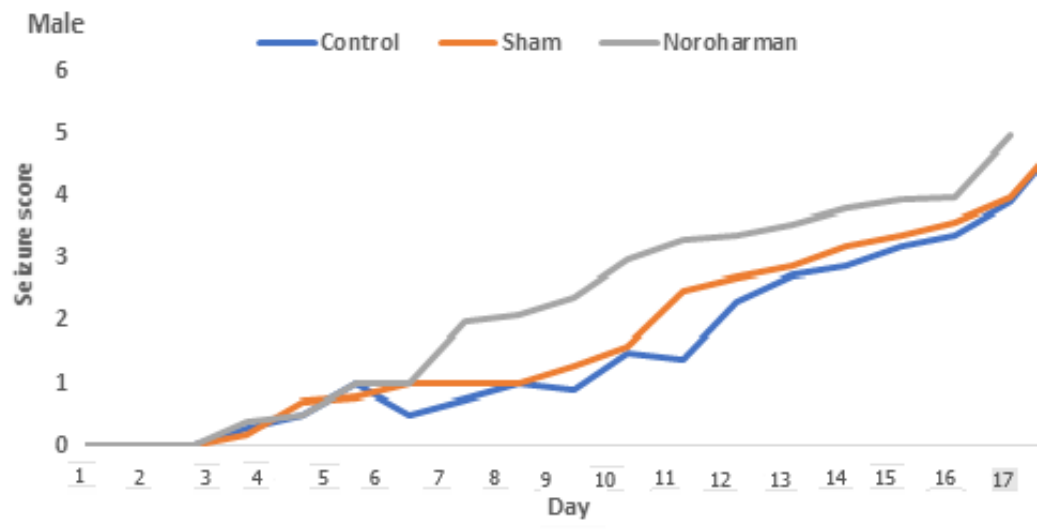

Figure 2. Comparing the mean scores of seizures induced by PTZ in the male rats

The consumption of norharman shortened stage 4 of seizures, compared to the controls. 


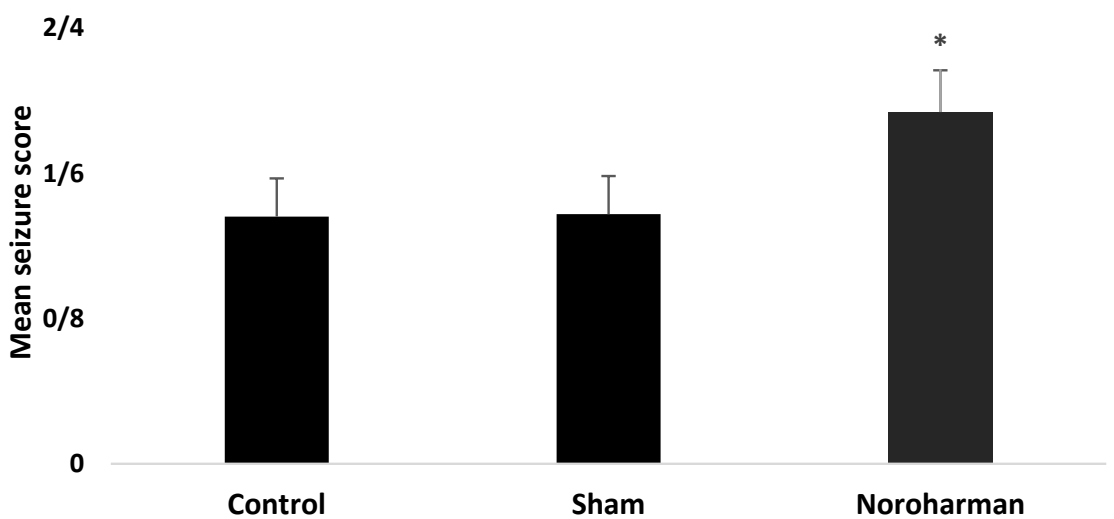

Figure 3. Comparing the Mean \pm SEM scores of PTZ-induced seizures in female rats

Journal of

Inflammatory Diseases

The score of PTZ-induced seizures in female animals of the norharman group was higher than those in the control and sham groups; $\mathrm{n}=8$. ${ }^{*} \mathrm{P}<0.05$, compared with the control group.

process reduces the mental capacity of newborn mice [21]. Besides, prenatal stress is dangerous and can play a role in causing congenital neurological diseases. For example, stress during pregnancy changes the activity of the hypothalamic-pituitary-adrenal axis of the fetus; this mechanism changes the structure and function of the brain in response to some stimulus of the CNS [18, 22].

Norharman is a beta-carboline alkaloid that can activate serotonin receptors. It also inhibits the enzyme monoamine oxidase and hydrogen and sodium exchanger [12, 13]. The fetal period is a critical life stage in which the CNS is evolving and growing. In this context, a defect in the evolution of the GABAergic system has been detected in mice that received benzodiazepines during pregnancy. The GABAergic system plays an essential role in reducing the brain's sensitivity to the activity of excitatory systems $[18,19]$.
Norharman is a benzodiazepine receptor reverse agonist; when used in the prenatal period, it may present detrimental effects on the inhibitory systems of the brain [14]. In adult mice, binding to the GABA receptor reduces the capacity of chlorine channels to open in response to the GABA anticonvulsant substance [23]. Beta-Carbolines have been described as co-enzyme. This is because they cause other mutant compounds. Receiving norharman in the embryonic period can lead to changes in DNA replication as well as the enzymatic activity involved in the process of modifying DNA sequences in eukaryotic and prokaryotic cells. Norharman also directly or indirectly prevents DNA repair; thus, it enhances mutations induced by ultraviolet or mutagenic chemicals [10].

Norharman has been reported to indirectly increase the release of oxygen free radicals that cause oxidative

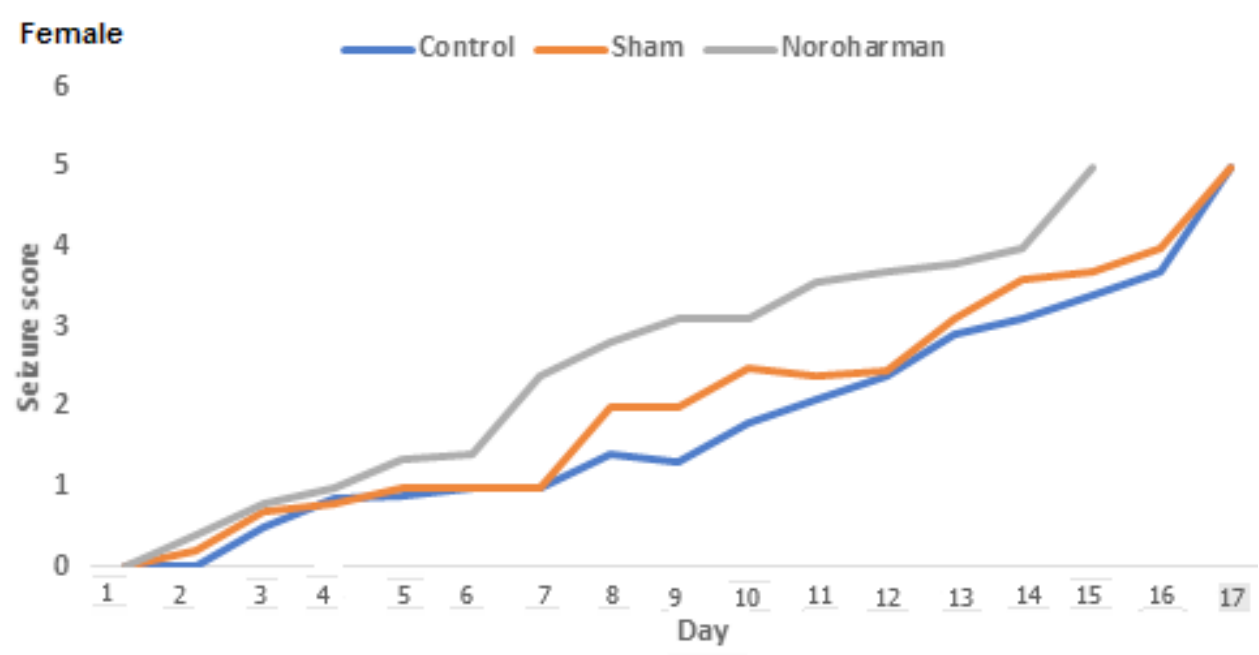

Figure 4. Comparing the mean score of seizures induced by PTZ in female rats 
stress, cell apoptosis, or necrosis. The increment level of free radicals and neuroinflammation affect the incidence of epilepsy [24]. Norharman also inhibits chaperon GRP 78 function by binding to it and reduces cellular energy stores by inhibiting the enzyme triphosphate isomerase and altering the glycolysis pathway. Subsequently, these adverse effects can cause neural permanent damage. Therefore, this evidence could explain the increasing effects of norharman on the susceptibility of the CNS to seizures-inducing substances [16, 25]. Accordingly, another mechanism proposed is the effects of norharman as a competitive inhibitor of the enzyme monoamine oxidase, which increases the concentration of serotonin in tissues. Moreover, these alkaloids can bind to serotonin receptors, as a regulatory molecule that regulates the natural balance between excitatory and inhibitory neurotransmission [26]. Monoamine-Oxidase (MAO) regulates the levels of dopamine, serotonin, and noradrenaline in nerve tissue. Besides, it is required for proper nerve growth due to the dual role of monoamines in neurotransmission and morphogenesis. Studies reported that decreased MAO activity in rats before or during pregnancy leads to changes in fetal brainstem development and the response of offspring to auditory stimuli [27].

\section{Conclusion}

Overall, the present study data revealed that using norharman in the pregnancy period, possibly through molecular changes in the level of neurons, like inhibitory neurons damaging, promotes an imbalance between inhibitory and stimulatory factors in the brain. Furthermore, it predisposes to increased seizures in animals when seizure chemicals are received. Prenatal norharman consumption may generate the same effect in humans, which requires further studies. However, explaining the underlying mechanisms of such long-term effects in offspring is difficult and involves numerous genetic, epigenetic, growth, and environmental factors. According to the obtained results, it may be advisable for pregnant mothers to limit the consumption of substances containing large amounts of beta-carboline during pregnancy.

\section{Ethical Considerations}

\section{Compliance with ethical guidelines}

This study was approved by the Ethics Committee of Qazvin University of Medical Sciences (IR.QUMS. REC.1399.064).

\section{Funding}

The paper was extracted from the thesis at Department of Physiology, Faculty of Medicine, Qazvin University of Medical Sciences.

\section{Authors' contributions}

Conceptualization and Supervision: Mohammad Hossein Esmaeili; Methodology, Investigation, Writing original draft, and Writing - review \& editing: Mohammad Sofiabadi; Data collection and Data analysis: Amin Afshar.

\section{Conflict of interest}

The authors declared no conflicts of interest.

\section{Acknowledgments}

The authors appreciate the Vice Chancellor for Research of Qazvin University of Medical Sciences and all those who have accompanied us in conducting this study.

\section{References}

[1] Freestone DR, Karoly PJ, Cook MJ. A forward-looking review of seizure prediction. Curr Opin Neurol. 2017; 30(2):16773. [DOI:10.1097/WCO.0000000000000429] [PMID]

[2] Martindale JL, Goldstein JN, Pallin DJ. Emergency department seizure epidemiology. Emerg Med Clin North Am 2011; 29(1):15-27. [DOI:10.1016/j.emc.2010.08.002] [PMID]

[3] Bhalla D, Godet B, Druet-Cabanac M, Preux PM. Etiologies of epilepsy: A comprehensive review. Expert Rev Neurother. 2011; 11(6):861-76. [DOI:10.1586/ern.11.51] [PMID]

[4] Stafstrom CE. Pathophysiological mechanisms of seizures and epilepsy: A primer. In: Rho J, Sankar R, Stafstrom CE, editors. Epilepsy: Mechanisms, Models, and Translational Perspectives. Boca Raton: CRC Press. 2010. pp. 3-19. https:// books.google.com/books?id=8prMBQAAQBAJ\&dq

[5] Wilden JA, Cohen-Gadol AA. Evaluation of first nonfebrile seizures. Am Fam Physician. 2012; 86(4):334-40. [PMID]

[6] Havasimehr M, Saffarzadeh F, Divanbeigi A, Karimzadeh F. A review on the animal models of seizure: Review article. Tehran Univ Med J. 2018; 76(2):79-89. [In Persian] http:// tumj.tums.ac.ir/article-1-8767-en.html

[7] Karimzadeh F, Jafarian M, Gharakhani M, Razeghi Jahromi S, Mohamadzadeh E, Khallaghi B, et al. Behavioural and histopathological assessment of the effects of periodic fasting on pentylenetetrazol-induced seizures in rats. Nutr Neurosci. 2013 16(4):147-52. [DOI:10.1179/1476830512Y.0000000039] [PMID] 
[8] Karimzadeh F, Modarres Mousavi SM, Ghadiri T, Jafarian M, Soleimani M, Mohammad Sadeghi Sh, et al. The modulatory effect of metabotropic glutamate receptor type-1a on spike-wave discharges in WAG/Rij rats. Mol Neurobiol. 2017; 54(2):846-54. [DOI:10.1007/s12035-016-9692-x] [PMID]

[9] Piechowska P, Zawirska-Wojtasiak R, Mildner-Szkudlarz S. Bioactive $\beta$-carbolines in food: A review. Nutrients. 2019; 11(4):814. [DOI:10.3390/nu11040814] [PMID] [PMCID]

[10] Cao R, Peng W, Wang Z, Xu A. $\beta$-carboline alkaloids: Biochemical and pharmacological functions. Curr Med Chem. 2007; 14(4):479-500. [DOI:10.2174/092986707779940998] [PMID]

[11] Farzin D, Mansouri SN. Evaluation of anti-depressant activities of harmane, norharmane and harmine in mice. J Gorgan Univ Med Sci. 2004; 6(2):1-9. [In Persian] http://goums. ac.ir/journal/article-1-194-en.html

[12] Esmaeili MH, Sofiabadi M, Haghdost H, Lotfi A, Najafi M. Effects of norharmane on memory retention in passive avoidance learning in rats. J Sabzevar Univ Med Sci. 2015; 22(5):862 9. [In Persian] http://jsums.medsab.ac.ir/article_765.html

[13] Farzin D, Kalantari P, Zaer H. Effects of harmane, norharman and harmine on the hot-plate and formalin-induced nociception in mice. J Mazandaran Univ Med Sci. 2012 22(87):87-95. [In Persian] http://jmums.mazums.ac.ir/article-1-1292-en.html

[14] Morin AM, Watson AL, Wasterlain CG. Kindling of seizures with norharman, a $\beta$-carboline ligand of benzodiazepine receptors. Eur J Pharmacol. 1983; 88(1):131-4. [DOI:10.1016/0014-2999(83)90402-8]

[15] Esmaeili M, Hassani M, Ashouri M, Amanea Goragi R, Mosavi F. Effects of chronic administration of norharman on spatial learning and memory in female rats. J Inflamm Dis. 2014; 18(2):39-45. [In Persian] http://journal.qums.ac.ir/article-1-1566-en.html

[16] Bonnet R, Pavlovic S, Lehmann J, Rommelspacher H. The strong inhibition of triosephosphate isomerase by the natural beta-carbolines may explain their neurotoxic actions. Neuroscience. 2004; 127(2):443-53. [DOI:10.1016/j.neuroscience.2004.05.002] [PMID]

[17] Naga T, Yoshimura S, Totsuka Y, Wakabayashi K. Maternal and developmental toxicity in mice by aminophenylnorharman, formed from norharman and aniline. Hum Exp Toxicol. 2002; 21(3):147-51. [DOI:10.1191/0960327102ht227oa] [PMID]

[18] Pivina SG, Shamolina TS, Akulova VK, Ordian NE. Sensitiveness to social stress in female rats with alteration of the pituitary-adrenal axis stress reactivity. Ross Fiziol Zh Im I M Sechenova. 2007; 93(11):1319-25. [In Russian] [PMID]

[19] Rössler AS, Schröder H, Dodd RH, Chapouthier G, Grecksch G. Benzodiazepine receptor inverse agonist-induced kindling of rats alters learning and glutamate binding. Pharmacol Biochem Behav. 2000; 67(1):169-75. [DOI:10.1016/ S0091-3057(00)00312-9]

[20] Šlamberová R, Schindler CJ, Pometlová M, Urkuti C, Purow-Sokol JA, Vathy I. Prenatal morphine exposure differentially alters learning and memory in male and female rats. Physiol Behav. 2001; 73(1-2):93-103. [DOI:10.1016/S00319384(01)00469-3] [PMID]

[21] Chiou LC, Yeh GC, Fan SH, How CH, Chuang KC, Tao PL. Prenatal morphine exposure decreases analgesia but not $\mathrm{K}^{+}$channel activation. Neuroreport. 2003; 14(2):239-42. [DOI:10.1097/00001756-200302100-00016] [PMID]

[22] Gagin R, Cohen E, Shavit Y. Prenatal exposure to morphine alters analgesic responses and preference for sweet solutions in adult rats. Pharmacol Biochem Behav. 1996; 55(4):629-34. [DOI:10.1016/S0091-3057(96)00278-X]

[23] Haghdoost Yazdi H, Movahedi M, Faraji A, Sofiabadi M. Norharman exacerbates 6-hydroxydopamine-induced Parkinson's disease but cannot establish it alone. Physiol Pharmacol. 2011; 15(2):261-7. [In Persian] https:/ / www.sid.ir/fa/ journal/ViewPaper.aspx?ID=147827

[24] Ho YH, Lin YT, Wu CW, Chao YM, Chang AYW, Chan JYH. Peripheral inflammation increases seizure susceptibility via the induction of neuroinflammation and oxidative stress in the hippocampus. J Biomed Sci. 2015; 22(1):46. [DOI:10.1186/s12929-015-0157-8] [PMID] [PMCID]

[25] Roland BP, Stuchul KA, Larsen SB, Amrich CG, Vandemark AP, Celotto AM, et al. Evidence of a triosephosphate isomerase non-catalytic function crucial to behavior and longevity. J Cell Sci. 2013; 126(14):3151-8. [DOI:10.1242/ jcs.124586] [PMID] [PMCID]

[26] Wrońska AK, Boguś MI. Harman and norharman, metabolites of the entomopathogenic fungus Conidiobolus coronatus (Entomophthorales), affect the serotonin levels and phagocytic activity of hemocytes, insect immunocompetent cells, in Galleria mellonella (Lepidoptera). Cell Biosci. 2019; 9:29. [DOI:10.1186/s13578-019-0291-1] [PMID] [PMCID]

[27] Beyrouty P, Stamler CJ, Liu JN, Loua KM, Kubow S, Chan HM. Effects of prenatal methylmercury exposure on brain monoamine oxidase activity and neurobehaviour of rats. Neurotoxicol Teratol. 2006; 28(2):251-9. [DOI:10.1016/j. ntt.2005.12.007] [PMID] 